\title{
Low-Fat Set Yogurt Made from Milk Subjected to Combinations of High Hydrostatic Pressure and Thermal Processing
}

\author{
F. Harte, ${ }^{\star}$ L. Luedecke,† B. Swanson,† and G. V. Barbosa-Cánovas \\ *Biological Systems Engineering Department, Washington State University, Pullman 99164-6120 \\ †Department of Food Science and Human Nutrition, Washington State University, Pullman 99164-6376
}

\begin{abstract}
The combined use of high hydrostatic pressure $(300$ to $676 \mathrm{MPa}, 5 \mathrm{~min})$ and thermal treatment $\left(85^{\circ} \mathrm{C}, 30\right.$ min) in milk for the manufacture of low-fat yogurt was studied. The objective was to reduce syneresis and improve the rheological properties of yogurt, reducing the need for thickeners and stabilizers. The use of high hydrostatic pressure alone, or after thermal treatment, reduced the lightness and increased the viscosity of skim milk. However, milk recovered its initial lightness and viscosity when thermal treatment was applied after high hydrostatic pressure. The MALDI-TOF spectra of skim milk presented monomers of whey proteins after a treatment of $676 \mathrm{MPa}$ for $5 \mathrm{~min}$. Yogurts made from skim milk subjected to 400 to $500 \mathrm{MPa}$ and thermal treatment showed increased yield stress, resistance to normal penetration, and elastic modulus, while having reduced syneresis when compared to yogurts from thermally treated or raw milks. The combined use of thermal treatment and high hydrostatic pressure assures extensive whey protein denaturation and casein micelle disruption, respectively. Although reaggregation of casein submicelles occurs during fermentation, the net effect of the combined HHP and thermal treatment is the improvement of yogurt yield stress and reduction of syneresis.
\end{abstract}

(Key words: high hydrostatic pressure, syneresis, yield stress, yogurt)

Abbreviation key: $\boldsymbol{\alpha}$-La $=\alpha$-Lactalbumin, $\boldsymbol{\beta}$-Lg $=\beta$ Lactoglobulin, HHP = high hydrostatic pressure, WHC = whey holding capacity.

\section{INTRODUCTION}

The consumption of yogurt has steadily increased over the last $30 \mathrm{yr}$ in the United States (Economic Research Service, 2000), Canada (Agri-Food Canada,

Received October 12, 2002.

Accepted November 26, 2002.

Corresponding author: G. V. Barbosa-Cánovas; e-mail: barbosa @wsu.edu.
2002), and many European countries (European Dairy Association, 2002). Most of this increase is attributed to the healthy image associated with yogurt and other dairy products.

During yogurt manufacture, the thermal treatment of milk before fermentation promotes the denaturation of whey proteins (mainly $\boldsymbol{\beta}$ - $\mathbf{L g}$ and $\boldsymbol{\alpha}$-La) and their interaction through disulfide linkages with $\kappa$-casein on the casein micelle surface. The "coating" effect of the whey proteins on the micelle surface prevents the coalescence of micelles when fermentation drops the $\mathrm{pH}$ to the isoelectric point of casein. In this way, instead of exhibiting clumps of micelles and gels with very weak structure and low whey retention observed in yogurts made from raw milk, yogurts made from thermally treated milk exhibit a thin micelle matrix that impairs firmness and increases whey retention.

Although thermal treatment increases firmness and reduces syneresis of yogurt, stabilizers and thickeners are added to the milk to optimize the rheological and whey retention properties.

High hydrostatic pressure (HHP) can alter the structure of proteins, inactivate enzymes, and inactivate microorganisms, but the basic mechanisms involved are only partially understood (Hummer et al., 1998; Palou et al., 1999).

The denaturing effect of HHP on whey proteins is documented (Hinrichs et al., 1996; Huppertz et al., 2002), although complete denaturation remains under discussion, because molten globule state was suggested for $\beta$-Lg at $600 \mathrm{MPa}$ (Yang et al., 2001), and defined secondary structure has been observed after pressure as high as $1000 \mathrm{MPa}$ (Panick et al., 1999). The disruption of casein micelles by relatively low pressure was also demonstrated through different methods (Needs et al., 2000; Harte et al., 2002a; Huppertz et al., 2002; Kelly et al., 2002).

The HHP processing of milk before fermentation in the production of yogurt resulted in increased solid-like behavior and whey retention properties of the yogurt, with other properties unaffected by the HHP treatment (Needs et al., 2000; Ferragut et al., 2000; Harte et al., 2002b) or simulated yogurt (Johnston et al., 1994; Famelart et al., 1997; Walsh-O'Grady et al., 2001). The 
successful application of HHP on already fermented yogurt to prevent postacidification was reported by Tanaka and Hatanaka (1992, in Johnston, 1995) and de Ancos et al. (2000).

While Harte et al. (2002b) reported similar yield stress values in set yogurts made from whole milk subjected to $85^{\circ} \mathrm{C}$ for $30 \mathrm{~min}$ or $676 \mathrm{MPa}$ for $30 \mathrm{~min}$, WalshO'Grady et al. (2001) concluded that the thermal treatment of milk was better in producing casein/whey protein interaction than HHP treatment $(700 \mathrm{MPa}$ for $20 \mathrm{~min}$ ).

The objective of this research was to characterize low-fat set yogurts obtained from fortified skim milk subjected to combinations of HHP and thermal processing conditions. It is hypothesized that extensive whey protein denaturation induced by thermal treatment, coupled with the disrupting effect of HHP on casein micelles may yield yogurts having reduced syneresis and improved rheological properties. The reduction in syneresis and increase of elastic properties is the main goal to achieve in the quest of a low-fat set yogurt free from stabilizers and thickeners.

\section{MATERIALS AND METHODS}

\section{Applied Treatments and Yogurt Manufacture}

Fresh raw milk (3.55 to $3.60 \%$ milkfat, 3.25 to $3.27 \%$ protein) was purchased from the Washington State University (WSU) Dairy Creamery and skimmed to $0.4 \%$ fat using a cream separator. The milk was fortified with $4 \%$ (wt/wt) grade A low-heat nonfat dry milk powder (Westfarm Foods, Seattle, WA), held in plastic bags $(700 \mathrm{ml})$ at $4^{\circ} \mathrm{C}$ for less than $2 \mathrm{~h}$, and subjected to the following treatments: 1) HHP (300, 400, 500, and 676 $\mathrm{MPa}$ for $5 \mathrm{~min}) ; 2$ ) thermal $\left(85^{\circ} \mathrm{C}\right.$ for $\left.30 \mathrm{~min}\right)$; 3) HHP then thermal; 4) thermal then HHP and, 5) control (no treatment). High hydrostatic pressure was applied using an isostatic pressing system (Engineered Pressure Systems, Inc., Haverhill, MA) having a cylindrical pressure chamber (height $=0.25 \mathrm{~m}$, dia $=0.10 \mathrm{~m}$ ) and a come-up time $\sim 45 \mathrm{~s} / 100 \mathrm{MPa}$. After treatments, the milk was cooled to $\sim 5^{\circ} \mathrm{C}$ and inoculated using $1.5-\mathrm{ml}$ of starter culture in $700 \mathrm{ml}$ of fortified milk. The starter culture was prepared as a 1:5 (wt/vol) dilution of frozen YC-087 culture (CHR Hansen Inc., Milwaukee, WI) in sterile skim milk $\left(121^{\circ} \mathrm{C} ; 15 \mathrm{~min}\right)$ and maintained in liquid nitrogen until inoculation. Incubation was held at $43^{\circ} \mathrm{C}$ for $5 \mathrm{~h}$. After incubation, the yogurt gels were held at $4^{\circ} \mathrm{C}$ for $36 \mathrm{~h}$ before further determinations. A completely randomized block design with two replications was used. Each batch of fresh raw milk receiving a set of 14 treatments constituted a block.

\section{Determinations in Milk}

Fifty $\mathrm{ml}$ of milk from each treatment was set aside at $4^{\circ} \mathrm{C}$ in the presence of $0.1(\mathrm{wt} / \mathrm{vol}) \mathrm{NaN}_{3}$ until $\mathrm{pH}$ determination. Lightness $\left(\mathrm{L}^{*}\right)$ values (CIELAB scale for standard light source D65 and $10^{\circ}$ observer) were recorded for milk and yogurt using a CM-2002 colorimeter (SCE mode, Minolta Camera, Co., Japan). Viscosity was calculated from flow curves $\left(0\right.$ to $200 \mathrm{~s}^{-1}$ at $\left.5^{\circ} \mathrm{C}\right)$ using an AR-1000 rheometer (TA Instruments, New Castle, DE) equipped with a cone and plate geometry (40 mm diameter, $3^{\circ} 59^{\prime \prime}$ angle, $0.116-\mathrm{mm}$ truncation). Viscosity was measured for all replicates. The charge to mass spectra for $\alpha$-La and $\beta$ - $\mathrm{Lg}$ in one replication of each treated milk was obtained using a Voyager-DE time-of-flight mass spectrometer (Applied Biosystems, Foster City, CA), following procedures described by Fedele et al. (1999). Briefly, $10 \mu \mathrm{l}$ of milk was dissolved in $1 \mathrm{ml}$ of $0.1 \%$ (wt/vol) trifluoriacetic acid in water. Five micro liters of this solution was added to $5 \mu \mathrm{l}$ of matrix. A 1:1 (vol/vol) saturated sinapinic acid (in acetonitrile) and water solution was used as the matrix. One microliter of the resulting mixture was deposited on the MALDI-TOF sample holder. The sample was ionized by a 337-nm nitrogen laser pulse and accelerated under $25000 \mathrm{~V}$ before entering the mass spectrometer. Each charge-to-mass spectrum was the sum of 100 laser pulses.

\section{Determinations in Yogurt}

Lightness $\left(\mathrm{L}^{*}\right)$ values were recorded as described for milk. To determine $\mathrm{pH}$, a 1:1 (wt/vol) solution of yogurt and $0.2 \% \mathrm{NaN}_{3}$ in distilled water was made immediately after the incubation period and set aside at $4^{\circ} \mathrm{C}$. Rheological determinations were made using the AR1000 rheometer at constant temperature $\left(5^{\circ} \mathrm{C}\right)$. Yield stress was calculated as the peak stress when subjecting the yogurt to a constant angular velocity $(0.042$ $\mathrm{s}^{-1}$ ) stress (Steffe, 1996) using a four-blade vane geometry (14-mm outer radius; $2.8-\mathrm{mm}$ inner radius; $20-\mathrm{mm}$ height). Elastic modulus ( $\left.\mathrm{G}^{\prime}\right)$ was recorded under oscillatory mode using a plate and plate texturized geometry (20-mm diameter; $1.5-\mathrm{mm}$ gap) at constant shear stress $(0.6 \mathrm{~Pa})$ within the linear viscoelastic region $(\gamma<0.01 \%)$, and a $0.01-10 \mathrm{~Hz}$ frequency range. Average data from two samples per replicate and two replicates per treatment were used to model the change in $\mathrm{G}^{\prime}$ as affected by the frequency of oscillation using a power law model (Steffe, 1996). Resistance to normal penetration was evaluated by a back extrusion test using a TA-XT2 texture analyzer (Texture Technologies, Scarsdale, NY) and subjecting the yogurt in a cylindrical container (27$\mathrm{mm}$ ID $\times 46-\mathrm{mm}$ height $)$ to a constant speed $(2 \mathrm{~mm} / \mathrm{s})$ penetration using a $25-\mathrm{mm}$ diameter flat cylindrical 
geometry. One sample from each replicate was used for the penetration studies.

For whey holding capacity (WHC), yogurts were subjected to 15 -min centrifugation at $15000 \times g$ at room temperature. The following formula was used to calculate WHC: WHC $(\%)=[1$ - (weight of whey after centrifugation/yogurt weight)]*100. Syneresis was calculated as the percent area occupied by whey after draining the yogurt container $(26 \mathrm{~mL})$ upside down for 6 min on grade-50 filter paper (Whatman, Clifton, $\mathrm{NJ}$ ).

Yogurts cut into 2- $\mathrm{mm}^{3}$ cubes were prepared for transmission electron microscopy (TEM) by submerging into 0.05- $M$ PIPES buffer ( $\mathrm{pH} 7.2$ ) containing $1.25 \%$ glutaraldehyde and $2.00 \%$ paraformaldehyde for $24 \mathrm{~h}$ at $4^{\circ} \mathrm{C}$ for fixation. After three washes (10 min each) in PIPES buffer, the cubes were dehydrated through serial 10 -min washes in $30,50,70$, and $95 \%$ ethanol in distilled water. Dehydration was completed with three 10min washes in $100 \%$ ethanol. The fixed yogurt cubes were infiltrated using a $1: 1(\mathrm{v} / \mathrm{v})$ medium-grade LR White resin (London Resin Company, Ltd., Reading, England) in $100 \%$ ethanol for $12 \mathrm{~h}$ at $4^{\circ} \mathrm{C}$. The cubes were left in $100 \% \mathrm{LR}$ White for $12 \mathrm{~h}$ at $4^{\circ} \mathrm{C}$ (three times) and cured in $100 \% \mathrm{LR}$ White for $12 \mathrm{~h}$ at $60^{\circ} \mathrm{C}$. Ninety nanometer sections of the fixed and cured yogurt gel samples were obtained using a Reichert ultracut microtome (Leica Microsystems Inc., Chicago, IL).

\section{RESULTS AND DISCUSSION}

\section{Milk}

While the $\mathrm{pH}$ of milk (average $\mathrm{pH}$ 6.68) was not affected by the different HHP and thermal treatments, HHP exhibited a marked effect on the milk color (Figure 1). The milk subjected to HHP or thermal treatment and then HHP, lost its typical white color to a yellowish color resembling milk whey. The change to a yellow color was most probably the result of a decrease in the casein micelle size due to the HHP (Needs et al., 2000; Harte et al., 2002a), which, in turn, would make the milk translucent, exposing the whey. Milk subjected to HHP and then thermal treatment recovered its original white color, similar to the thermally treated and raw milks. The recovery of the initial color of milk indicates that the disruption of the casein micelles induced by HHP (from 300 to $676 \mathrm{MPa}$ ) is reversible if milk is subjected to an adequate thermal treatment.

The high $\mathrm{L}^{*}$ values (increased whiteness) observed in milk subjected to HHP and then thermal treatment (Figure 2) also support the hypothesis of reaggregation of disrupted micelles. However, whether thermal reaggregation resulted in micelles of larger size than micelles in raw milk remains to be elucidated since reached a certain critical size of the micelle, the $L^{*}$ value remains constant independently of the micelles' growth, i.e., the milk does not get whiter above a certain size in the casein micelle (Walstra, 1996). Although the HHP treatment reduced the lightness of raw or thermally treated milks, little further decrease was observed when milk was subjected to HHP $>300 \mathrm{MPa}$ (Figure 2). These results confirm lightness and turbidity data reported by Desobry-Banon et al. (1994) and Needs et al. (2000) and suggest that little additional micelle disruption occurs with exposure of casein micelles to pressures $>300 \mathrm{MPa}$. Although similar to the naked eye, milk subjected to thermal treatment and then HHP exhibited a slight increase in lightness when compared to milk subjected to HHP only. As reported by Harte et al. (2002a), the HHP processing of thermally treated suspensions containing casein micelles and whey proteins resulted in disrupted micelles exhibiting larger size than casein micelle isolates (void of whey proteins) subjected to the same treatment conditions. It was concluded that the thermal denaturation of whey proteins and their interaction with the $\kappa$-casein on the surface of the micelle resulted in a protection of the micelle to the HHP-induced disruption.

The combination of HHP and thermal treatments rather than the level of the high pressure exerted a greater effect on the viscosity of fortified milk (Figure $3)$. Increased pressures resulted in the disappearance of the monomeric forms of both $\alpha-\mathrm{La}$ and $\beta-\mathrm{Lg}$ (Figure 4) of fortified milks and were not reflected in a change in viscosity. The increase in viscosity of fortified milk after HHP treatment (Figure 3) cannot be explained entirely from a micelle disruption standpoint only. One of the most widely-accepted models describes the casein micelle as a sphere formed by spherical casein submicelles bound by colloidal calcium phosphate (Walstra, 1999). As predicted by Einstein's equation (Barnes et al., 1989) or its modification for concentrated dispersions by Eilers (Snoeren et al., 1982), the viscosity of solid spheres in suspension depends mainly on the volume fraction of the spheres in suspension and not on their diameter. If the disruption of large spherical micelles into small, spherical submicelles is the only effect induced by HHP, viscosity will remain unchanged in milk subjected to thermal treatment and HHP-treated milk. The HHP-induced liberation of colloidal calcium phosphate and individual caseins concentrating the serum in which submicelles are suspended may explain the increase in viscosity. In the case of fortified milk subjected to thermal treatment and then HHP, the high viscosity values may be the result of 1) extensive denaturation of whey proteins and disulfide interaction on the surface of the casein micelles induced by the thermal treatment (sustained by the fact that no monomeric forms of the whey proteins were observed after thermal 


\begin{tabular}{|c|c|c|c|c|}
\hline $\begin{array}{c}\text { Pressure } \\
(\mathrm{MPa})\end{array}$ & $\begin{array}{l}\mathrm{HHP} \\
\vee\end{array}$ & $\begin{array}{c}\text { Thermal } \rightarrow \mathrm{HHP} \\
\vee\end{array}$ & $\begin{array}{c}\text { HHP } \rightarrow \text { Thermal } \\
\qquad\end{array}$ & $\begin{array}{c}\text { Raw and } \\
\text { Thermal } \\
\vee\end{array}$ \\
\hline $300 \rightarrow$ & & & & \\
\hline $400 \rightarrow$ & & & & \\
\hline $500 \rightarrow$ & & & 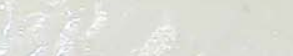 & \\
\hline $676 \rightarrow$ & & & & \\
\hline
\end{tabular}

Figure 1. Color of fortified milk subjected to high hydrostatic pressure (HHP) and thermal treatment combinations.

treatment; Figure 4), and 2) the subsequent HHP-induced disruption of micelles into submicelles of irregular shape derived from their thermally induced interaction with the whey proteins. Having the same micelle volume fraction, the loss of sphericity will increase the viscosity of particles in suspension (Barnes et al., 1989).

Similar to lightness, fortified milk subjected to HHP and then thermal treatment exhibited equivalent viscosity when compared to the viscosity of thermally treated or raw milk. This observation also supports the hypothesis of a reaggregation effect of thermal treatment on HHP-disrupted casein micelles.

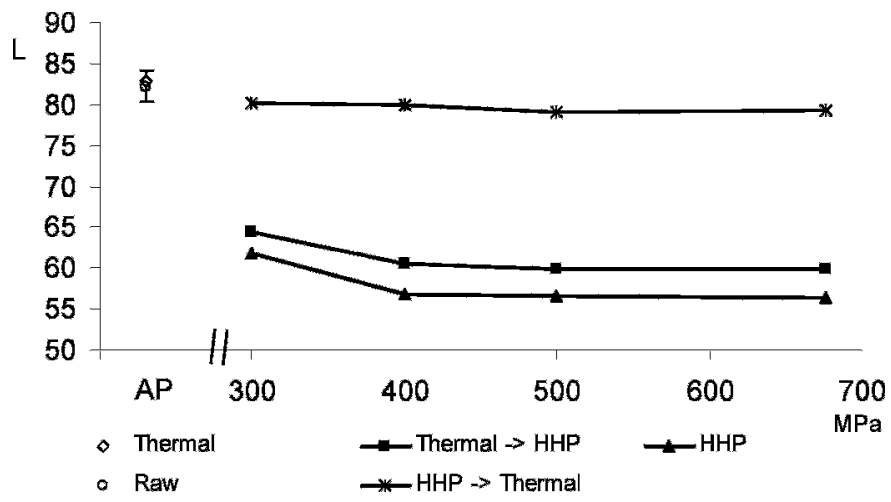

Figure 2. Average lightness of fortified milk subjected to selected combinations of HHP and thermal treatments. AP: Atmospheric pressure. Bar is a $95 \%$ confidence interval for any mean.
Although the denaturing effect of HHP on whey proteins is well-documented, monomeric forms of both whey proteins were observed in the MALDI-TOF spectra after subjecting the milk to pressures of $676 \mathrm{MPa}$ for 5 min (Figure 4). As reported elsewhere (Hinrichs et al., 1996), $\alpha$-La exhibited greater resistance to denaturation than $\beta$-Lg. Monomeric $\beta$-Lg and $\alpha$-La were absent from milk subjected to thermal treatment independently of receiving HHP, indicating extensive denaturation. The decrease in monomeric forms of the whey proteins was accompanied by extensive polymerization,

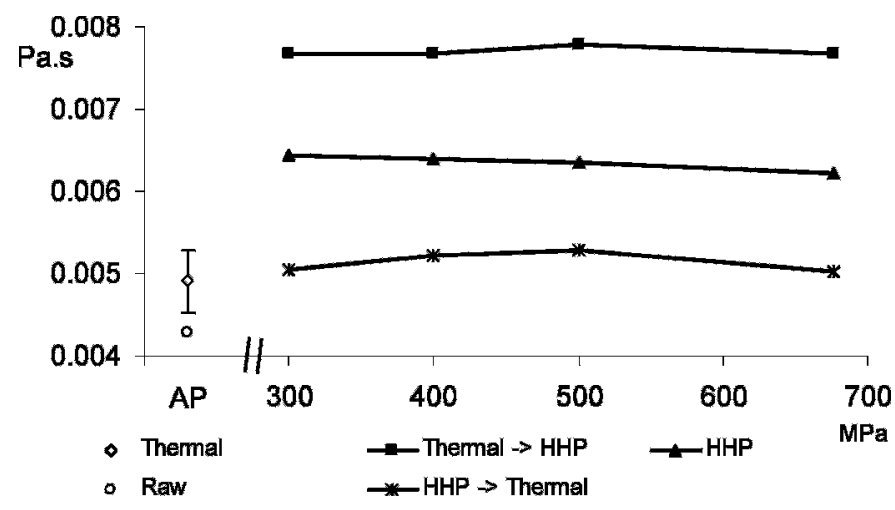

Figure 3. Average viscosity of fortified milk subjected to selected combinations of HHP and thermal treatments. AP: Atmospheric pressure. Bar is a $95 \%$ confidence interval for any mean. 

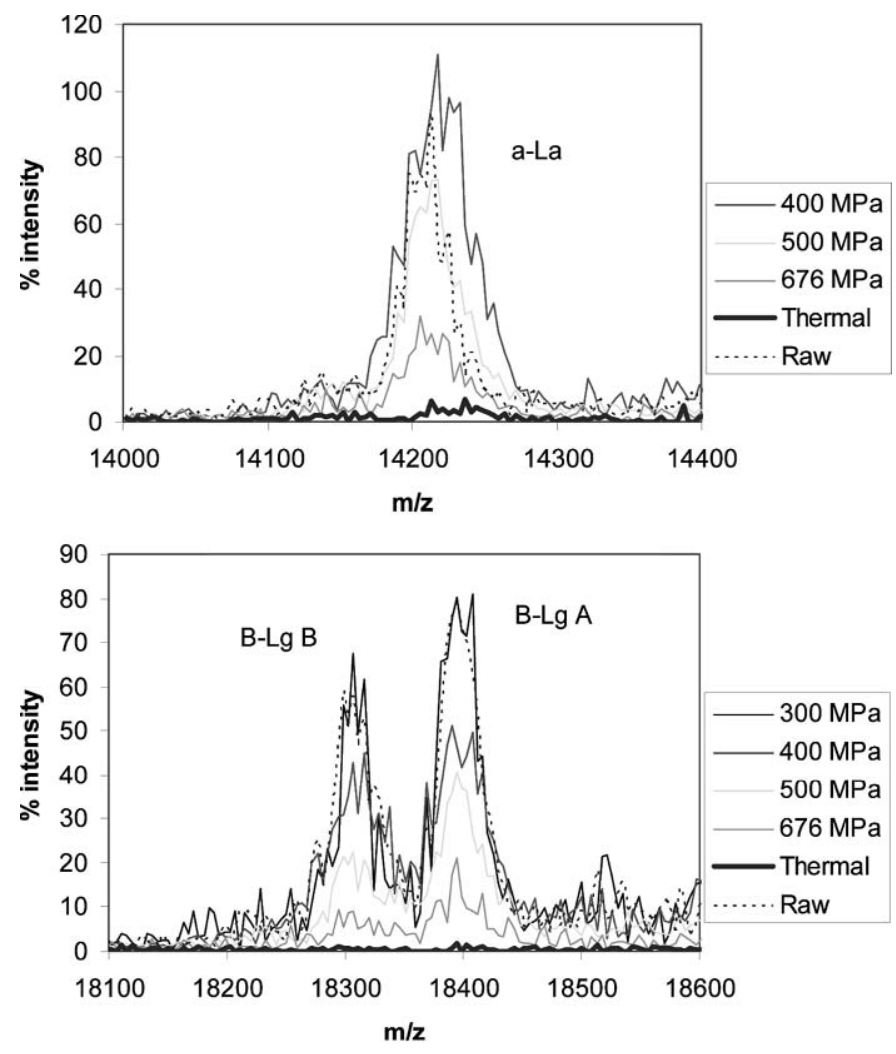

Figure 4. MALDI-TOF spectra for monomeric $\beta$-lactoglobulin $(\beta$ $\mathrm{Lg})$ and $\alpha$-Lactalbumin $(\alpha$-La) in milk subjected to selected pressures and thermal treatment.

evidenced by the lack of dimer, trimer, or tetramer forms of the $\beta$-Lg and $\alpha$-La in the MALDI-TOF spectra.

\section{Yogurt}

The $\mathrm{pH}$ of yogurts was not significantly affected by the treatment applied to fortified milk. While Needs et al. (2000) reported that the rate of $\mathrm{pH}$ decay during fermentation of yogurts made with skim milk and $10 \%$ solids was affected by the applied HHP treatment to the milk, the $\mathrm{pH}$ at the end of the incubation period was equivalent for the different yogurts regardless of the applied treatment with an average $\mathrm{pH}$ of 4.64 and a $0.26 \%$ coefficient of variation.

Aggregation of casein micelles during fermentation into larger aggregates made the observed $\mathrm{L}^{*}$ values the same for all experimental yogurts independently of the previous treatment applied to the milk (Figure 5). The change to similar lightness patterns does not suggest a similar casein micelle matrix in the different yogurts. The white color of yogurt does not change depending on the aggregation pattern or the size of the casein micelle fraction, i.e., the color of yogurts made from raw or thermally treated milk is the same, while the casein

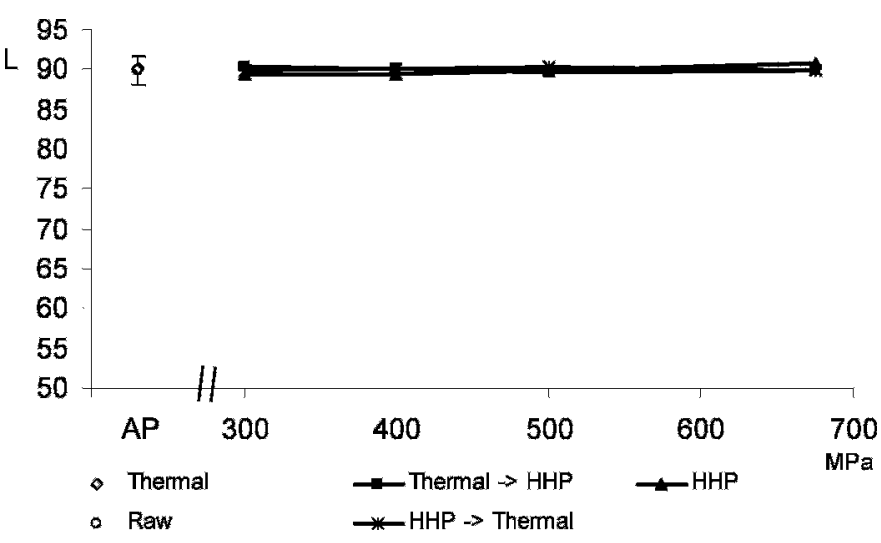

Figure 5. Average lightness of yogurts made from fortified milk subjected to selected HHP and thermal combination treatments. AP: Atmospheric pressure. Bar is a 95\% confidence interval for any mean.

micelle aggregation pattern is different (Aguilera and Stanley, 1999).

Although all yogurts were similar in appearance, their rheological and whey retention properties were different. Yogurts from combined HHP and thermally treated, fortified milk exhibited increased yield stress when compared to other treatments, independent of the specific pressure (Figure 6). The pressure exhibited effect on yield stress in yogurts made from milk subjected to HHP only was consistent with increased denaturation of whey proteins at higher pressures. In yogurts made from fortified milk thermally treated before or after the HHP treatment, the denaturation was achieved by the thermal treatment; hence, the effect of HHP was mainly to disrupt casein micelles, which is

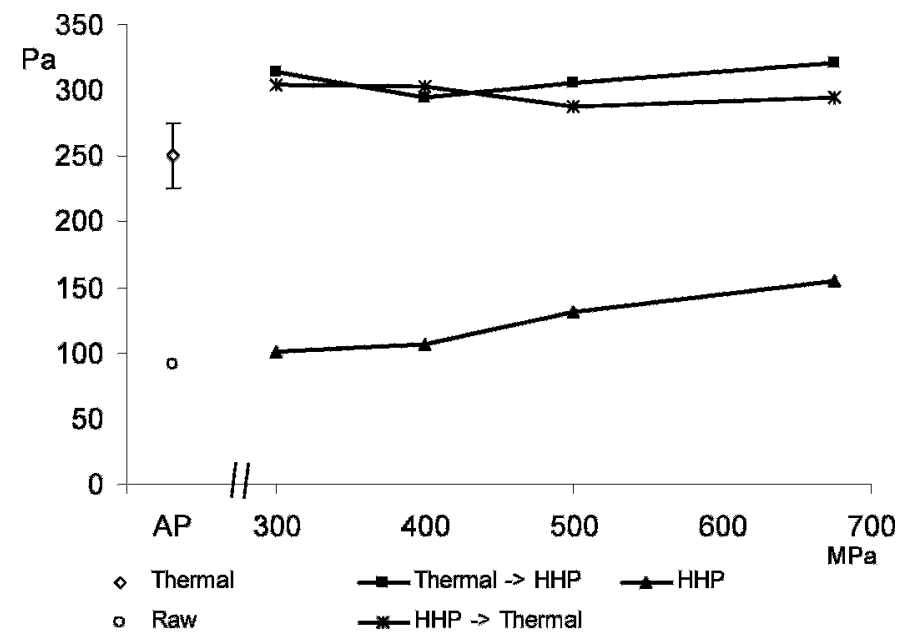

Figure 6. Average yield stress $(\mathrm{Pa})$ of yogurts made from fortified milk subjected to selected HHP and thermal combination treatments. AP: Atmospheric pressure. Bar is a 95\% confidence interval for any mean. 


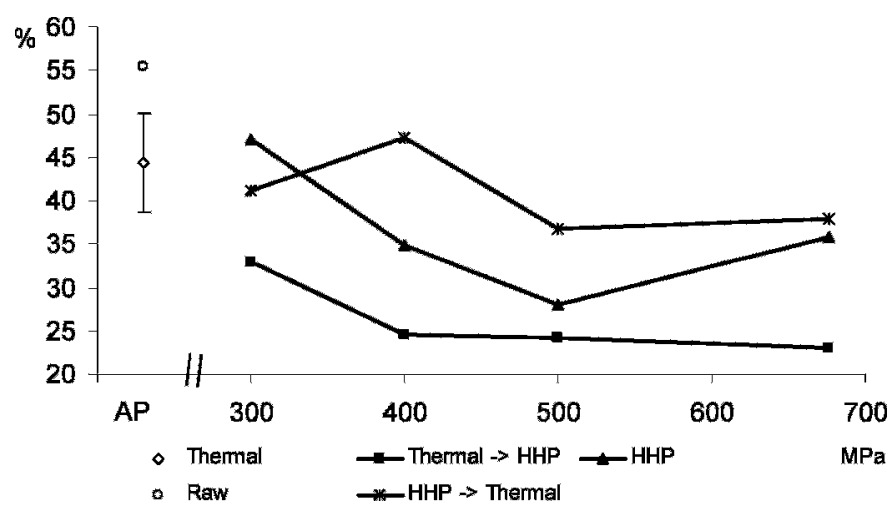

Figure 7. Average syneresis of yogurts made from fortified milk subjected to selected HHP and thermal combination treatments. AP: Atmospheric pressure. Bar is a 95\% confidence interval for any mean.

achieved with lower pressures $(>300 \mathrm{MPa})$. The yield stress values obtained with the vane geometry method at constant rotational speed were greater than yield stress values reported elsewhere for set-yogurt (Harte et al., 2002b). Haque et al. (2001) suggested that the shearing, when subjecting yogurt to rotational parallel plates, would promote microsyneresis of the gels which may favor slippage of the geometry and underestimation of yield stress. When the yogurt gels were subjected to normal penetration at constant velocity, the force per unit distance exhibited the same trend as for yield stress $(\mathrm{r}=0.98)$.

The determination of yogurt whey-retention properties has been previously reported by using different measuring methods ( Van Vliet et al., 1991; Johnston et al., 1998; Schkoda et al., 1999). When determined by centrifugation, yogurts made from HHP-only-treated fortified milk exhibited the highest whey retention properties, while yogurts from other treatments except raw milk exhibited lower whey retention values, not significantly different from each other. However, when whey retention was evaluated as whey separated from yogurt on a filter paper, yogurts made from fortified milk subjected to thermal treatment and then HHP $>400 \mathrm{MPa}$ exhibited higher whey retention (Figure 7). Since the concept of syneresis is related to whey weakly bound and thus easily expelled by the yogurt gel, the evaluation using the filter paper method was considered best suited to represent syneresis.

Yogurts made from combined HHP and thermallytreated milk exhibited increased elastic properties (Figure 8), particularly at intermediate pressures of 400 and $500 \mathrm{MPa}$. Yogurts made from HHP-only-treated milk did not exhibit a significantly different elastic modulus $\left(G^{\prime}\right)$ when compared to yogurts made from raw milk. Greater values of $G^{\prime}$ and yield stress were expected for yogurts made from fortified milk subjected

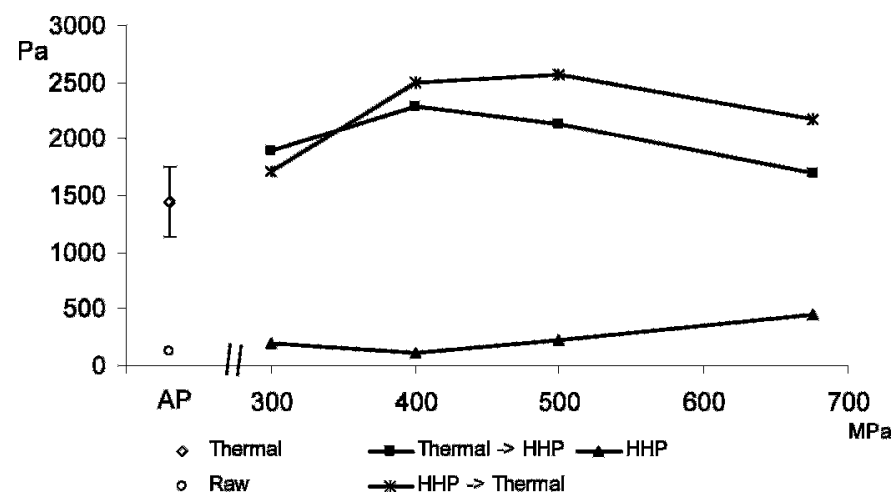

Figure 8. Average elastic modulus $\left(\mathrm{G}^{\prime} ; \omega=6.28 \mathrm{~s}^{-1}\right)$ of yogurts made from fortified milk subjected to selected HHP and thermal combination treatments. AP: Atmospheric pressure. Bar is a $95 \%$ confidence interval for any mean.

to pressures $>500 \mathrm{MPa}$ as reported by Needs et al. (2000) in fat free yogurt containing $10.4 \%$ solids, and Harte et al. (2002c) in full-fat yogurt containing $10 \%$ solids. However, the yogurts made in these experiments contained a smaller amount of fat $(0.4 \%)$ and/or total solids $(7.25 \%)$, suggesting that fat*HHP or whey protein*HHP interaction may have an important effect on the rheological properties of yogurts made from HHPtreated milk.

During frequency sweep ( $\omega$ from 0.0628 to $6.28 \mathrm{~s}^{-1}$ ) at constant oscillatory stress $(0.6 \mathrm{~Pa})$, all yogurt gels exhibited good fitting $(\mathrm{r} \geq 0.99)$ to a power law model of the form $\mathrm{G}^{\prime}=\mathrm{K} \omega^{\mathrm{n}}$ (Table 1) with low dependence on the frequency (weak gel behavior). Both the intercept $(\mathrm{K})$ and slope (n) of the linearized model were higher for yogurts made from milk subjected to combined HHP and thermal treatment when compared to yogurts made from HHP only or raw milks. Furthermore, $\mathrm{K}$ values were an order of magnitude greater than $K$ values from yogurts made from HHP only or raw milk.

Transmission electron micrographs were obtained for yogurts made from thermally treated milk, raw milk, and from milk subjected to combined HHP (300 and 676 $\mathrm{MPa}$ ) and thermal treatments (Figure 9). As expected, yogurts made from raw milk exhibited micelles of irregular size and areas of extensive coalescence. Yogurts from milk subjected to $676 \mathrm{MPa}$ for 5 min exhibited round micelles of smaller and more homogeneous size as compared to yogurts from thermally treated milk which exhibited round micelles of irregular size and rough edges. Yogurts from combined $676 \mathrm{MPa}$ and thermal treatment exhibited similar microstructure independent of the thermal treatment applied after or before HHP. Reaggregation of submicelles during fermentation may explain why yogurts from milk subjected to $300 \mathrm{MPa}$ and thermal treatment exhibited similar 
Table 1. Power law model adjustment for the elastic modulus $\left(\mathrm{G}^{\prime}=\mathrm{K} \omega^{\mathrm{n}}\right)$ of yogurts subjected to frequency sweep $\left(0.0628\right.$ to $\left.6.28 \mathrm{~s}^{-1}\right)$ under constant shear stress $(0.6 \mathrm{~Pa}){ }^{1}$

\begin{tabular}{|c|c|c|c|c|c|c|c|c|c|}
\hline \multirow{2}{*}{$\begin{array}{l}\text { Pressure } \\
(\mathrm{MPa})\end{array}$} & \multicolumn{3}{|c|}{ Thermal $\rightarrow$ HHP } & \multicolumn{3}{|c|}{ HHP } & \multicolumn{3}{|c|}{ HHP $\rightarrow$ Thermal } \\
\hline & $\mathrm{K}$ & $\mathrm{n}$ & $\mathrm{r}$ & $\mathrm{K}$ & $\mathrm{n}$ & $\mathrm{r}$ & $\mathrm{K}$ & $\mathrm{n}$ & $\mathrm{r}$ \\
\hline 300 & 1479 & 0.181 & 0.992 & 140 & 0.188 & 0.993 & 1340 & 0.180 & 0.995 \\
\hline 400 & 1682 & 0.174 & 0.996 & 88 & 0.185 & 0.990 & 1840 & 0.174 & 0.997 \\
\hline 500 & 1569 & 0.176 & 0.995 & 160 & 0.202 & 0.991 & 1877 & 0.178 & 0.996 \\
\hline 676 & 1284 & 0.172 & 0.998 & 324 & 0.199 & 0.992 & 1580 & 0.179 & 0.997 \\
\hline Raw & 93 & 0.185 & 0.986 & & & & & & \\
\hline Thermal & 1062 & 0.173 & 0.998 & & & & & & \\
\hline
\end{tabular}

${ }^{1} \mathrm{HHP}=$ high hydrostatic pressure.

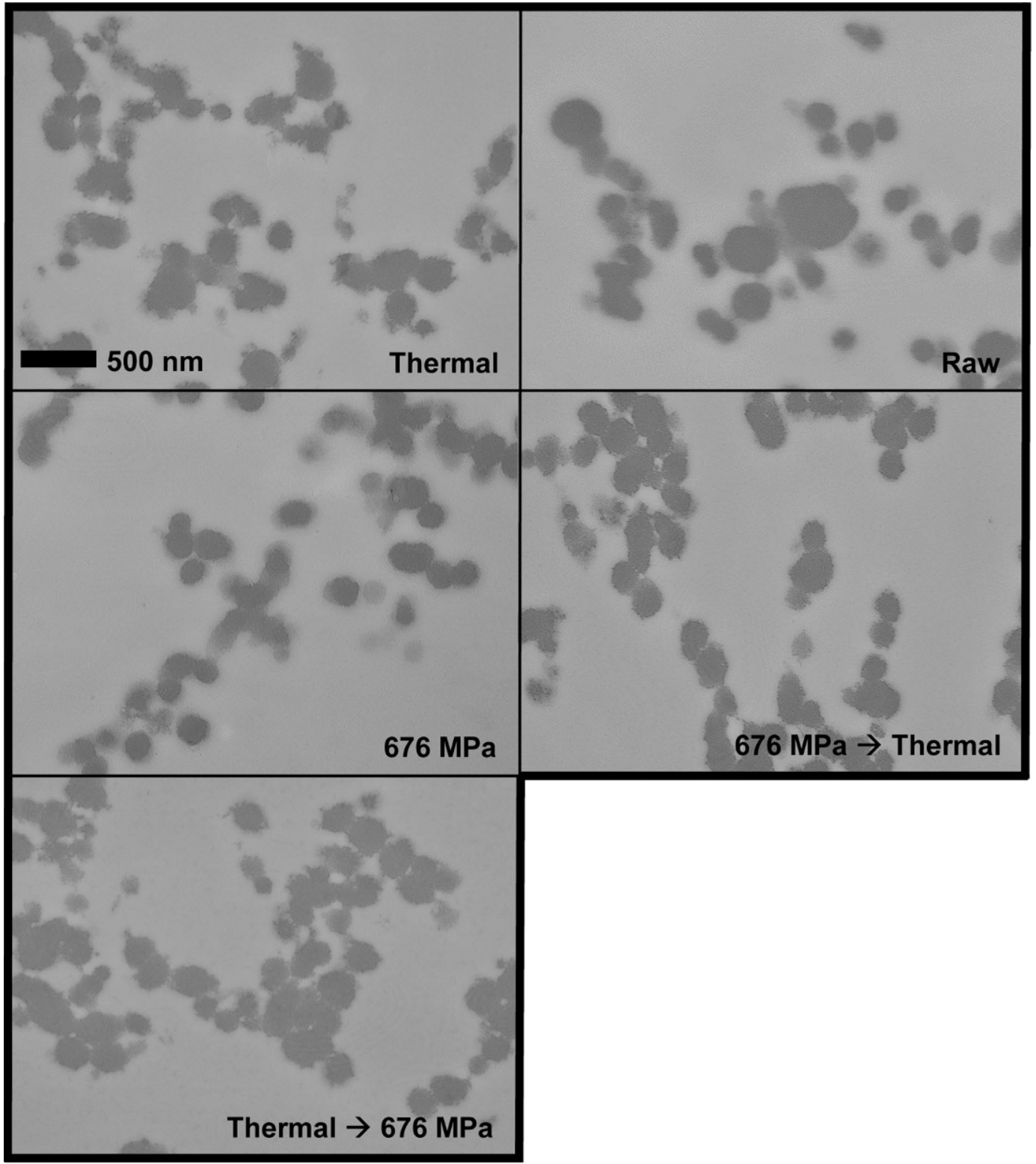

Figure 9. Transmission electron micrographs of yogurts prepared from fortified milk subjected to combination of $\mathrm{HHP}$ (676 MPa, 5 min) and thermal $\left(85^{\circ} \mathrm{C}, 30 \mathrm{~min}\right)$ processing. 
microstructure to yogurts from only thermally treated milk. Yogurts made from milk subjected to $676 \mathrm{MPa}$ and thermal treatment showed casein micelles of intermediate size. As evidenced by the lightness and viscosity determinations (Figures 2 and 3), thermal treatment after HHP processing promoted the reaggregation of micelles which resulted in microstructures of these yogurts similar to microstructure of yogurts made from thermally-treated milk. Yogurts from thermally and then HHP-treated milk also exhibited similar microstructure to only thermally treated milk. This observation is, in principle, contradictory with results reported by Harte et al (2002a) showing disruption of micelles into submicelles after HHP treatment of heated casein micelle isolates. However, the denaturing effect of a thermal treatment on the whey proteins of milk and reaggregation of the casein micelles during yogurt fermentation may explain the observed results.

\section{CONCLUSIONS}

The combined use of HHP and thermal treatments for fortified low-fat milk resulted in yogurts exhibiting improved elastic modules and yield stress as well as reduced syneresis, particularly in the intermediate $\mathrm{HHP}$ range of 400 to $500 \mathrm{MPa}$. Although reaggregation of casein submicelles during fermentation of yogurt may occur, the use of thermal treatment to assure extensive whey protein denaturation combined with HHP to disrupt casein micelles provides a tool for manufacturing yogurts with less stabilizers (due to less syneresis) and less thickeners (due to increased elastic modulus and yield stress).

\section{ACKNOWLEDGMENTS}

This research was funded in part by a grant from the IMPACT Center at Washington State University. The authors kindly acknowledge the technical assistance from the Electronic Microscopy Center at Washington State University and Scott Krane (TA Instruments) for loaning the rheometer.

\section{REFERENCES}

Agri-Food Canada. 2002. Per capita consumption of dairy products. http://www.dairyinfo.agr.ca/dpconsumption.pdf. Accessed June $30,2002$.

Aguilera, J. M. and D. W. Stanley. 1999. Microstructural principles of food processing and engineering. 2nd ed. Aspen Publishers, NY.

Barnes, H. A., J. F. Hutton, and K. Walters. 1989. An introduction to Rheology. Elsevier Science. Amsterdam, The Netherlands.

de Ancos, B., M. P. Cano, and R. Gomez. 2000. Characteristics of stirred low-fat yogurt as affected by high pressure. Int. Dairy J. 10(1):105-111.

Desobry-Banon, S., F. Richard, and J. Hardy. 1994. Study of acid and rennet coagulation of high pressurized milk. J. Dairy Sci. 77(11):3267-3274.
Economic Research Service. 2002. Food consumption (per capita) data system. http://www.ers.usda.gov/data/foodconsumption/. Accessed June 30, 2002.

European Dairy Association. 2002. Figures. http://eda.euromilk. org/. Accessed July 5, 2002.

Famelart, M. H., F. Gaucheron, F. Mariette, Y. Le Graet, K. Raulot, and E. Boyaval. 1997. Acidification of pressure-treated milk. Int. Dairy J. 7(5):325-330.

Fedele, L., R. Seraglia, B. Battistotti, C. Pinelli, and P. Traldi. 1999. Matrix-assisted laser desorption/ionization mass spectrometry for monitoring bacterial protein digestion in yogurt production. J. Mass Spec. 34:1338-1345.

Ferragut, V., V. M. Martinez, A. J. Trujillo, and B. Guamis. 2000. Properties of yogurts made from whole ewe's milk treated by high hydrostatic pressure. Milchwissenschaft 55(5):267-263.

Haque, A., R. K. Richardson, and E. R. Morris. 2001. Effect of fermentation temperature on the rheology of set and stirred yogurt. Food Hydrocolloids 15(4-6):593-602. Online. Available: http://www.s ciencedirect.com/science/article/B6VP9-44GDHNS-13/1/a3f203 3aed9c16dbafaad552a5f920bc.

Harte, F. M., L. O. Luedecke, B. G. Swanson, and G. V. BarbosaCánovas. 2002a. Disrupting effect of high hydrostatic pressure on casein micelle isolates. IFT Annu. Mtd. Tech. Program Abstr., 130 (Abstr.).

Harte, F., M. Amonte, L. Luedecke, B. G. Swanson, and G. V. BarbosaCánovas. 2002b. Yield stress and microstructure of set yogurt made from high hydrostatic pressure-treated full fat milk. J. Food Sci. 67(6):2245-2250.

Harte, F. M., L. O. Luedecke, B. G. Swanson, and G. V. BarbosaCánovas. 2002c. Low-fat yogurt manufacture using high hydrostatic pressure and thermal processing. IFT Annu. Mtg. Tech. Program Abstr., 52 (Abstr.).

Hinrichs, J., B. Rademacher, and H. G. Kessler. 1996. Reaction kinetics of pressure-induced denaturation of whey proteins. Milchwissenschaft 51(9):504-509.

Hummer, G., S. Garde, A. E. Garcia, M. E. Paulaitis, and L. R. Pratt. 1998. The pressure dependence of hydrophobic interactions is consistent with the observed pressure denaturation of proteins. Proc. Nat. Acad. Sci. 95(4):1552-1554.

Huppertz, T., A. L. Kelly, and P. F. Fox. 2002. Effects of high pressure on constituents and properties of milk. Int. Dairy J. 12(7):561572. Online. Available: http://www.sciencedirect.com/science/ article/B6T7C-458P4CW-1/1/3dab4d3aac89a45a4aca7536e3f75 d40.

Johnston, D. E. 1995. High pressure effects on milk and meat. Pages 99-121 in High-pressure processing of foods. D.A. Ledward, D. E. Johnston, R. G. Earnshaw, and A. P. M. Hasting, ed. Nottingham University Press, United Kingdom.

Johnston, D. E., R. J. Murphy, and A. W. Birks. 1994. Stirred-style, yogurt-type product prepared from pressure-treated skim milk. High-pressure research. 12:215-219.

Johnston, D. E., R. J. Murphy, J. A. Rutherford, and C. A. McElhone. 1998. Formation and syneresis of rennet-set gels prepared from high-pressure-treated milk. Pages 220-226 in High-Pressure Food Science, Bioscience, and Chemistry. Vol. 222. Royal Society of Chemistry, Cambridge, United Kingdom.

Kelly, A. L., T. Huppertz, and P. F. Fox. 2002. Structural properties of casein micelles in high-pressure-treated milk. IFT Annu. Mtg. Tech. Program Abstr., 197 (Abstr.).

Needs, E. C., R. A. Stenning, A. L. Gill, V. Ferragut, and G. T. Rich. 2000. High-pressure treatment of milk: effects on casein micelle structure and on enzymic coagulation. J. Dairy Res. 67(1):31-42.

Palou, E, A. López-Melo, G. V. Barbosa-Cánovas, and B. G. Swanson. 1999. High-pressure treatment in food preservation. Pages 533577 in Handbook of Food Preservation. R. Shafiur, ed. Marcel Dekker, NY.

Panick, G., R. Malessa, and R. Winter. 1999. Differences between the pressure- and temperature-induced denaturation and aggregation of beta-lactoglobulin $\mathrm{A}, \mathrm{B}$, and $\mathrm{AB}$ monitored by FT-IR spectroscopy and small-angle X-ray. Biochem. 38(20):6512-6519.

Schkoda, P., A. Hechler, and H. G. Kessler. 1999. Effect of minerals and $\mathrm{pH}$ on rheological properties and syneresis of milk-based acid 
gels. Int. Dairy J. 9(3-6):269-274. Online. Available: http://www .sciencedirect.com/science/article/B6T7C-3X52FPN-N/1/1328fc 2da6a7f1595c67b5c03742ad9a.

Snoeren, T. H. M., A. J. Damman, and H. J. Klok. 1982. The viscosity of skim-milk concentrates. Neth. Milk Dairy J. 36(4):305-316.

Steffe, J. F. 1996. Rheological methods in food process engineering. 2nd ed. Freeman Press. East Lansing, MI.

Van Vliet, T., H. J. M. van Dijk, P. Zoon, and P. Walstra. 1991. Relation between syneresis and rheological properties of particle gels. Colloid and Polymer Sci. 269:620-627.

Walsh-O'Grady, C. D., B. T. O'Kennedy, R. J. Fitzgerald, and C. N. Lane. 2001. A rheological study of acid-set "simulated yogurt milk" gels prepared from heat- or pressure-treated milk proteins. Lait 81(5):637-650.

Walstra, P. 1996. Dispersed systems: basic considerations. Pages 95155 in Food Chemistry. O. R. Fenema, ed. Marcel Dekker, NY.

Walstra, P. 1999. Casein submicelles: Do they exist? Int. Dairy J. 9(3-6):189-192. Online. Available: http://www.sciencedirect.com/ science/article/B6T7C-3X52FPN-6/1/0c3e5207f47a5f92974ac91 f4d02051a.

Yang, J., A. K. Dunker, J. R. Powers, S. Clark, and B. G. Swanson. 2001. b-lactoglobulin molten globule induced by high pressure. J. Agric. Food Chem. 49(7):3236-3243. 